\title{
Interpretation and documentation of chest X-rays in the acute medical unit
}

\author{
Authors: Saurabh Bahl, ${ }^{A}$ Tahir Ramzan ${ }^{\text {B }}$ and Randy Maraj ${ }^{\mathrm{B}}$
}

\begin{tabular}{|c|c|c|c|c|c|c|}
\hline $\begin{array}{l}\text { Total } \\
\text { number } \\
\text { of } \\
\text { patients }\end{array}$ & $\begin{array}{l}\text { Number of } \\
\text { patients who } \\
\text { had CXR within } \\
24 \text { hours }\end{array}$ & $\begin{array}{l}\text { Number of } \\
\text { patients who did } \\
\text { not have CXR } \\
\text { documented } \\
\text { within } 24 \text { hours }\end{array}$ & $\begin{array}{l}\text { Number of } \\
\text { patients who } \\
\text { had CXR } \\
\text { documented } \\
\text { within } 24 \text { hours }\end{array}$ & $\begin{array}{l}\text { Average gap from } \\
\text { CXR performed to } \\
\text { documentation } \\
\text { among the } 69 \%\end{array}$ & $\begin{array}{l}\text { Number of } \\
\text { CXR reviewed } \\
\text { and results } \\
\text { documented } \\
\text { within an hour }\end{array}$ & $\begin{array}{l}\text { Average gap } \\
\text { between CXR } \\
\text { and radiologist } \\
\text { report }\end{array}$ \\
\hline 97 & $67 \%(65 / 97)$ & $31 \%(20 / 65)$ & $69 \%(45 / 65)$ & 8 hours & $31 \%(14 / 45)$ & 22 hours \\
\hline
\end{tabular}

\section{Introduction}

The chest X-ray (CXR) is considered a simple investigation that is carried on most medical admissions. The ionising radiation medical exposure regulations (IRMER) 2000 guidance states: 'The employer shall ensure that a clinical evaluation of the outcome of each medical exposure is carried out and recorded'. The Care Quality Commission wrote to all acute trust chief executives in July 2011 requiring them to audit the recording of radiological reports and to develop an improvement plan.

\section{Aims}

To review the medical records of patients admitted directly to our acute medical unit who underwent a CXR, to identify whether timely and correct interpretation was performed and to identify potential issues.

\section{Methods}

We carried out a prospective audit conducted over 5 days and looked at the time from CXR to documentation of results in the medical notes, and whether the interpretation of the CXR was accurate compared with the later radiologist's report. We also looked at how long it took for a radiology report to be available.

The standard used was that $100 \%$ of CXRs should have a result recorded in the notes by a clinician at a time when the result will influence the management of the patient (based on the Royal College of Radiology standards). Data were collected from all admissions from primary care during the audit period $(\mathrm{n}=97)$.

\section{Results}

See Table 1 . Only $4 \%(3 / 65)$ of patients had a radiologist's report available within 4 hours. In 18\% (8/45) of the cases with a clinician's report, the clinician's report and the radiologist's report was significantly different (for example, clear lungs instead of consolidation).

\section{Conclusions}

Timely and correct interpretation of CXRs can help guide correct treatment of patients. Delay in review or non-review of CXRs can lead to potential problems including incorrect treatment, delay in discharge, missed diagnoses, and added financial costs.

\section{Conflicts of interest}

None declared.
Authors: ${ }^{\mathrm{A} C}$ Central and North West London NHS Foundation Trust, London, UK; ${ }^{B}$ University Hospitals of Derby and Burton NHS Foundation Trust, Derby, UK 